\title{
Percepção materna Quanto ao apoio social recebido no cuidado às crianças prematuras no domicílio
}

Perception of the mothers concerning the received social support in home care to the premature children

Percepción de las madres sobre el suporte social en la atención domiciliária prestada a los niños prematuros

\author{
Angelita dos Santos Simioni', Lorena Teresinha Consalter Geib' \\ 'Universidade de Passo Fundo, Curso de Enfermagem. Passo Fundo Paulo, SP
}

Submissão: 03/0I/2008

Aprovação: 15/09/2008

\section{RESUMO}

Este estudo Qualitativo objetivou conhecer a percepção das mães de crianças nascidas prematuras acerca do apoio social recebido no domicílio para o cuidado das mesmas. Incluiu 12 mães de prematuros, maiores de 20 anos, da área de cobertura das Unidades de Saúde da Família de Passo Fundo-RS. Os dados foram obtidos por meio de entrevista semi-estruturada, genograma e ecomapa. A análise evidenciou as avós como construtoras e mantenedoras do ninho social; desalento do abandono e base segura; e a inclusão social promovida pelos amigos. $\mathrm{O}$ apoio social não suprido centrou-se no cuidado à criança e nas atividades domésticas. A percepção das mães revela um apoio predominantemente intra-familiar, cuja expansão permitiria configurar uma rede social mais efetiva para fortalecimento do cuidado materno.

Descritores: Prematuro; Saúde da família; Apoio social.

\begin{abstract}
This study of Qualitative approach aimed at knowing the perception of mothers of premature newborn concerning the social support received in the home care. The sample included 12 mothers of premature, older than 20 years, in the coverage area of Family Health Units of Passo Fundo-RS. The data were collected through semi-structured interview, genogram and echomap. The thematic analysis evidenced the grandmothers as builders and maintaining of the social nest; the discouragement of the abandonment; the safe base; and the social inclusion promoted by the friends. The social support not supplied is centered in the care to the newborn and in the activities of the home. This way, the mothers' perception reveals a predominant intrafamiliar support, whose expansion would allow configuring a more effective social net for the strengthness of the maternal care.
\end{abstract}

Descriptors: Infant, premature; Family health; Social support.

\section{RESUMEN}

Este estudio cualitativo, intentó a saber la percepción de las madres de los niños nacidos prematuros acerca del apoyo social recibido en la casa para el cuidado del niño. La muestra incluyó a 12 madres de prematuros, más viejas Que 20 años, en el área de cubiertura de las Unidades de Salud de la Familia de Passo Fundo-RS. El análisis temático de los datos reunidos a través de la entrevista semiestructurada, genograma y echomapa evidenció las abuelas como constructoras y mantenedoras del nido social; el desaliento del abandono y la base segura y la inclusión social promovida por los amigos. El apoyo social no proporcionado se centra en el cuidado al y en las actividades de la casa. La percepción de las madres revela un apoyo predominantemente intra-familia cuya expansión permitiría a configurar un precio neto social más eficaz al fortalecimiento del cuidado maternal.

Descriptores: Prematuro; Salud de la familia; Apoyo social. 


\section{INTRODUÇÃO}

A criança ao nascer apresenta-se com alguma imaturidade funcional, requerendo um ambiente capaz de suprir as suas necessidades básicas e oferecer-lhe proteção. No decorrer da gestação, a mãe desenvolve um estado de sensibilidade especial Que a capacita a compreender intuitivamente as necessidades do seu filho e de exercer, suficientemente bem, o cuidado materno. A Qualidade desse cuidado é assegurada, por sua vez, pelo ambiente propiciado à mãe, uma vez Que ela também ingressa num estado de necessidade especial de suporte e aconchego, requisito imprescindível para capacitá-la ao atendimento das necessidades da criança ${ }^{(1)}$. Essa função protetora cabe, inicialmente, aos familiares, podendo ser ampliada aos vizinhos e amigos. Esse tipo de proteção caracteriza o apoio social.

O apoio social foi definido como "o grau com Que relações interpessoais correspondem a determinadas funções (por exemplo, apoio emocional, material e afetivo), com ênfase no grau de satisfação do indivíduo com a disponibilidade e Qualidade dessas funções"(2). É compreendido também como um processo Que gera efeitos positivos tanto para Quem recebe como para Quem oferece o apoio, permitindo Que ambos tenham maior sensação de controle sobre suas vidas, ou seja, um processo Que possibilita às pessoas ampliarem a autonomia e a capacidade de assumir o cuidado de si (3). Esse apoio provém primariamente da família considerada uma unidade de cuidado onde se efetivam os relacionamentos em Que pessoas vivem juntas, comprometidas, formam uma unidade econômica, cuidam dos mais jovens, identificam-se entre si e no grupo a Que pertencem“"(4,5).

Em muitos casos, representa um recurso inestimável em momentos de vulnerabilidade da saúde, como acontece Quando uma gestação de risco culmina com parto prematuro, situação Que coloca o recém-nascido em risco de sobrevivência, tanto maior Quanto mais precoce for seu nascimento. No caso da prematuridade, não só Questões de natureza orgânica estão implicadas. O nascimento de uma criança prematura é um evento Que modifica a dinâmica familiar e gera nos pais ansiedade e medo em relação à sobrevivência do recém-nascido, à internação em unidades de cuidados intensivos (UTI), às intercorrências de saúde e à necessidade de acompanhamento atencioso ao seu crescimento e desenvolvimento.

Essa vivência torna-se difícil Quando os pais não contam com um grupo de familiares, amigos ou profissionais de saúde com Quem possam compartilhar essa experiência e de Quem possam obter ajuda para prestar os cuidados requeridos pela criança na volta ao domicílio. Algumas mães e pais não conseguem seguir em frente sem uma ajuda especial. Nessas circunstâncias, o suporte social possibilita à família encontrar um equilíbrio nas possíveis mudanças, favorecendo a adaptação às particularidades Que toda criança nascida prematura possa apresentar.

$\mathrm{Na}$ cascata de eventos biológicos, psicológicos e sociais relacionados com a sobrevivência infantil de crianças nascidas prematuras, o apoio social representa uma possibilidade de amparo e cuidado à criança, mediado pelo cuidado à mãe e, muitas vezes também ao pai, e efetivado pelas relações benéficas e construtivas proporcionadas pelos familiares, amigos e vizinhos. Mas é necessário Que a mãe possa perceber a existência desse suporte para não sucumbir aos acontecimentos desorganizadores do meio ambiente.

A percepção do apoio social envolve duas dimensões: a percepção da disponibilidade e a percepção da satisfação com o apoio social, ou seja, "a percepção de Que existe um número de pessoas disponíveis a Quem se pode recorrer em caso de necessidade e o grau de satisfação em relação a esse suporte disponível" (6).

A possibilidade de o indivíduo perceber o apoio recebido constitui um fator protetor de problemas fisiológicos, psicológicos e sociais, sendo compreendido hoje como um fator preditivo da saúde e da adaptação individual, com possibilidade ainda de aumentar a auto-estima, melhorar o estado de humor, diminuir o estresse e os sentimentos de solidão e fracasso ${ }^{(7-11)}$.

Particularmente no Que se refere às mães de crianças nascidas prematuras, devemos apostar Que ao se sentirem apoiadas elas se mostrarão seguras para assumir o cuidado da criança, estando aptas a ajudar a consubstanciar uma rede de continuidade de cuidados hospitalares ou ambulatoriais numa lógica de promoção da autonomia e da saúde. Disso emerge como pressuposto que o apoio social percebido protege a mãe contra as adversidades no atendimento ao recém-nascido prematuro, fortalecendo-a no enfrentamento das intercorrências de saúde.

Norteado por esse pressuposto, este estudo teve como objetivo conhecer a percepção das mães de crianças nascidas prematuras acerca do apoio social recebido no domicílio para o cuidado do recém nascido.

\section{METODOLOGIA}

Este é um estudo abordagem Qualitativa, também denominada de "interpretativa”, em razão de investigar a natureza dos fenômenos sociais (interações, comportamentos) com enfoque no sentido que as pessoas atribuem aos mesmos ${ }^{(8)}$. O caráter descritivo explicitase no relato detalhado das realidades existentes no cotidiano social do campo de pesquisa, conceituado "como o recorte que o pesquisador faz em termos de espaço, representando uma realidade empírica a ser estudada a partir das concepções teóricas, Que fundamentam o objeto da investigação" (9).

O estudo foi desenvolvido no município de Passo Fundo, integrante da Macrorregião Norte de Saúde do Estado do Rio Grande do Sul (RS). Esse município está dividido em seis distritos. A população estimada para 2007 é de 188.302 com uma taxa de crescimento anual de 1,9\% estimada para o período 2000-2006. A proporção de mulheres em idade fértil é de $64,7 \%$ da população feminina ${ }^{(10)}$. É pólo regional em saúde, contando com seis hospitais, cinco Centros de Atendimentos Integrados à Saúde, 16 Unidades Básicas de Saúde da Família, 23 Ambulatórios de Atendimento Básico. Conta com 113 leitos pediátricos, sendo 31 em Centros de Terapia Intensiva ${ }^{(1)}$. A taxa de prematuridade entre os nascidos vivos girou em torno de $8 \%$ nos últimos cinco anos ${ }^{(12)}$.

A população do estudo foi constituída pelas mães Que tiveram filhos nascidos com menos de 37 semanas de idade gestacional, no período de maio a junho de 2007 , residentes na zona urbana de Passo Fundo, em área de cobertura das Unidades de Saúde da Família. A amostra foi intencional e seu tamanho inicial de doze mães, porém o tamanho foi ampliado para 14, número determinado pela saturação dos dados. Foram estabelecidos como critérios de 
inclusão ser maior de 20 anos, não estar hospitalizada ou com filho hospitalizado e como critério de exclusão a comunicação verbal prejudicada.

Efetuou-se o rastreamento das mães a partir das Declarações de Nascidos Vivos (DNV). A coleta de dados foi feita entre o primeiro e terceiro mês de vida da criança por meio de entrevista individual semi-estruturada, genograma e ecomapa. As informações obtidas foram registradas em um formulário previamente testado com duas mães, Que não integraram a amostra, para verificar a necessidade de ajustes. O instrumento continha dados sociodemográficos, espaço para a construção do genograma e ecomapa e Questões norteadoras sobre a rede de apoio familiar, de vizinhança, grupo de convívio e apoio profissional relativas às dimensões investigadas: apoio material, apoio afetivo, apoio emocional, apoio de informação e interação social positiva. A entrevista foi conduzida a partir da elaboração do genograma e junto com a mãe. A triangulação das técnicas de entrevista, do genograma e ecomapa ${ }^{(13)}$ tinha o propósito de dar concretude à percepção materna acerca do apoio recebido no cuidado da criança nascida prematura no âmbito das relações intra e extra familiares.

O genograma é um diagrama Que detalha a configuração da família fornecendo as informações requeridas pelo pesQuisador sobre cada componente das diversas gerações. A sua construção é realizada junto com a família ou o membro participante do estudo, utilizando-se as orientações de normas e símbolos universais ${ }^{(13,14)}$.

O ecomapa também é um diagrama, porém diferencia-se do genograma por apresentar as relações entre a família e a comunidade. Ajuda a avaliar os apoios e suportes utilizados pela família ${ }^{(14)}$. Também denominado "Diagrama das Relações Sociais", é uma representação gráfica das relações, Que neste estudo, delimitou-se aos vínculos entre a mãe e suas redes de apoio psicossocial, dimensionando a força dos vínculos sociais. As características desse diagrama permitem interpretar o comportamento social das pessoas envolvidas e entender a estrutura social na Qual as redes são construídas e Que remetem para: a) as trocas (drogas, bens materiais, relações de amizade, cumplicidade, entre outras); b) os atores das trocas - envolvem as relações horizontais (dentro da mesma geração ou entre pessoas com o mesmo status no grupo) e relações verticais (tipo patrão/empregado, pais/filhos) e c) força das trocas - densidade dos vínculos (estreitos, fluidos, contínuos ou eventuais) ${ }^{(15)}$.

O ecomapa serviu para a identificação das dimensões funcionais de apoio social percebido e assim empregadas no Brasil por Griep et $\mathrm{al}^{(16)}$ e Pinto et $\mathrm{al}^{(17)}$ :

I - apoio material: refere-se à provisão de recursos e ajuda material, incluídas, por exemplo, a ajuda em dinheiro ou empréstimo de utensílios, em caso de necessidade emergencial; 2 - apoio afetivo: envolve demonstrações físicas de amor e afeto; 3 - apoio emocional: refere-se à expressão de carinho, compreensão, confiança, estima, afeto, escuta e interesse; 4 - apoio de informação: refere-se a disponibilidade de pessoas para a obtenção de conselhos ou orientações. É medido por meio do acesso dos indivíduos a aconselhamentos, sugestões, orientações e informações; 5 interação social positiva: é a disponibilidade de pessoas com Quem se divertir e relaxar ${ }^{(16,17)}$. Essas dimensões integram as escalas de apoio social empregadas em estudos Quantitativos e serviram de parâmetros para a avaliação da percepção sobre o apoio social recebido, numa abordagem Qualitativa. Atribui-se a essa abordagem a possibilidade de melhor explorar o mundo subjetivo das mães e suas relações com os atores sociais, incluindo os profissionais de saúde e de outros serviços (educacionais, assistenciais, entre outros), complementando a compreensão das dimensões de apoio identificadas.

As entrevistas foram realizadas no domicílio, em ambiente Que resguardava a privacidade da participante, em data e horário acordado entre as partes. Foram gravadas na íntegra em fitas cassete com consentimento formal das participantes. Após a transcrição literal, as fitas foram destruídas. Para preservar a identidade das participantes, nos instrumentos e no relato do estudo, foram utilizadas as letras $M$ seguidas dos números seqüenciais das entrevistas. Dessa forma, MI corresponde à primeira mãe entrevistada, M2 a segunda e assim sucessivamente. As falas foram descritas no estado natural em Que foram expressas na entrevista.

Para a análise dos conteúdos das entrevistas foi utilizada a modalidade temática, operacionalizada nas seguintes etapas: ordenação dos dados, classificação dos dados e análise final ${ }^{(18)}$.

O projeto foi aprovado pelo Comitê de Ética em Pesquisa da Universidade de Passo Fundo. O acesso às Declarações de Nascidos Vivos do Sistema de Informações de Nascidos Vivos (SINASC) foi autorizado pelo Secretário Municipal de Saúde do município de Passo Fundo.

\section{RESULTADOS E DISCUSSÃO}

A partir da análise do conteúdo das informações obtidas, podese elaborar as seguintes categorias à luz do referencial teórico adotado: 1) percepções sobre as fontes de apoio social recebida; 2) dimensões do apoio social percebido; 3) percepção em relação à necessidade de apoio social não suprido e das situações de maior necessidade de apoio social.

\section{Percepções sobre as fontes de apoio social recebida: as avós como construtoras do ninho social}

As mudanças Que ocorrem nas diferentes fases do ciclo vital nascimento, ingresso na escola, início da vida profissional, casamento, maternidade/paternidade, envelhecimento e morte renovam os desafios, oportunidades e riscos não só para a família nuclear, mas para a família extensiva e pessoas de seu círculo de relações. No caso do nascimento, a forma como os pais reagem a esse evento pode influenciar a vida e o bem-estar atual e futuro do filho. $\mathrm{O}$ apoio social nesse momento de adaptação à nova dinâmica familiar tem uma importância muito grande na vida de cada pessoa e em particular para as mulheres em período puerperal. $\mathrm{O}$ apoio recebido torna-se fundamental para a manutenção da saúde materna, diminuindo distúrbios na relação familiar e auxiliando no comportamento materno.

As fontes de apoio são constituídas pelos suportes familiares (marido, avós, tios), não familiares (amigos, vizinhos, empregada e outros), instituições (serviços de saúde, escola, outros) e profissionais (médicos, enfermeiros, assistentes sociais, professores, dentre outros).

As mães de recém-nascidos prematuros, em sua maioria, percebem o apoio social advindo predominantemente de seu núcleo familiar com destaque para as sogras e as mães, Que constituíram 
as fontes de apoio mais significativas, seguidas pelas cunhadas e maridos. Essa realidade confirma a forte presença das avós maternas e paternas-, na construção social da família, como se pode evidenciar nestas falas:

A minha sogra Que me ajuda sempre que eu peço uma ajuda na casa, fazer comida, ajuda em tudo. (M3)

\section{Minha mãe me ajudou muito, minha sogra mora uma Quadra daqui também veio me ajudou e me apoiou muito, meu sogro também. (M2)}

A interação estabelecida pelas avós no momento do nascimento de um recém-nascido foi constatada em vários estudos prévios, Que evidenciaram o apoio fornecido pela avó paterna durante a hospitalização e após o nascimento da criança ${ }^{(19)}$. Esse apoio materializou-se no auxílio nas tarefas domésticas, além de informações, cuidados físicos, emocionais e materiais. Em contrapartida, alguns estudos sobre a rede social durante a expansão da família, constataram a ausência da família do companheiro como fontes de ajuda ${ }^{(20)}$.

No momento em Que a dinâmica familiar é alterada pela incorporação de um novo membro, a experiência advinda das gerações anteriores é colocada à disposição dos novos pais, com o propósito de ajudar na adaptação da família e de amenizar as inseguranças e fortalecer as competências parentais nesta fase de transição. Esse tipo de convívio da família ligada à criança realça a relação pais-filho, oportunizando a mãe realizar as transições psicológicas inevitáveis de adaptação à situação de prematuridade da criança $^{(20)}$. Dessa forma, a mãe estará equipada para alcançar sua identidade materna, porque terá experenciado equilíbrio interno, confiança e competência no desempenho do seu papel(21).

As instituições e os profissionais, incluindo os de saúde, foram percebidos de forma muito esmaecida pelas mães entrevistadas, restringindo-se a ser mais uma fonte de informação técnica do Que um agente de cuidado, com co-responsabilização e participação nos problemas sociais da família. Evidencia-se o distanciamento, especialmente dos serviços e profissionais do cotidiano do cuidado comunitário, entendido como aquele Que aproxima a assistência institucional e a não-institucional, a formal e a informal (parentesco, amigos, vizinhos) ${ }^{(22)}$.

\section{Dimensões do apoio social percebido}

$\mathrm{O}$ apoio social envolve alguns aspectos como apoio emocional, ajuda instrumental, informação sobre o meio, retro alimentação pessoal, rede de interações, comportamentos de apoio e percepção do apoio recebido ${ }^{(23)}$. Existem fatores-chave Que fazem parte da estrutura do apoio social, Que são o componente constitucional, relacional, funcional, estrutural e de satisfação, Que são observados e avaliados pelo grau de satisfação emocional e bem-estar pessoal ${ }^{(24)}$.

Neste estudo, evidenciamos as seguintes dimensões de apoio social:

Apoio material: a manutenção do ninho

$\mathrm{O}$ apoio recebido e mais fortemente percebido pelas mães foi a ajuda para os afazeres domésticos, expresso nas seguintes falas:

Minha sogra me ajuda na casa faz comida sempre Que eu peço. (M4)
Minha irmã lavava as roupas, cuidava da casa, faz companhia pra mim. (MI1)

\section{[...] meu marido que limpava a casa lavava a roupa [...].(MI2)}

A ajuda na divisão de responsabilidades foi entendida como apoio material por se aproximar mais desta dimensão do Que das demais analisadas pelo ecomapa.

Esse tipo de apoio possibilitou a essas mães ficar mais tempo à disposição de seus filhos recém-nascidos e também dormir e descansar nos momentos possíveis. Sentir-se confortada pela possibilidade de dedicar-se ao auto-cuidado e atendimento de suas necessidades básicas, permite à mãe conservar as energias necessárias às adaptações à criança e ao ambiente nos primeiros três meses pós-parto. A incapacidade de efetuar essas adaptações poderá produzir uma sensação de jamais ter feito tudo o Que era necessário ${ }^{25}$. A ajuda nos afazeres domésticos converte-se, assim, em apoio externo imprescindível para Que a mãe possa assumir os cuidados da criança, sem precisar compartilhá-los por mais tempo com outras pessoas, o Que diluiria seu sentimento de competência maternal(25).

\section{Apoio afetivo e emocional:}

a) o desalento do abandono

Embora algumas mães se sentissem amparadas, outras se sentiram abandonadas e carentes de apoio após a alta hospitalar, o Que ocasionou sentimentos de abandono, falta das pessoas Queridas, depressão e a grande necessidade de uma pessoa para conversar e contar seus medos, uma pessoa Que a fizesse sentir-se Querida e apoiada. Nos depoimentos a seguir observou-se Que as mães percebem a falta de apoio nos momentos em Que a rede social não supre as suas expectativas:

Queira Que minha mãe tivesse ficado comigo, o momento Que eu mais precisei dela ela ficou ausente (MI2)

\section{[...] minha sogra poderia ter ficado comigo e ela não ficou [...] (M9)}

Uma pessoa pra conversar, não tive apoio, não tive ninguém Que me fez sentir Querida. (MI0)

\section{[... I não tive apoio, tava indignada da vida, percebi que deixaram a desejar poderiam fazer mais e não fizeram, me sinto sozinha, eu senti Que fui meio esquecida eu senti Que sobrei [...].(MI0)}

No processo de adaptação à condição de mãe, a maioria das mulheres deseja ser acarinhada e cuidada. Emocionalmente, a pessoa permite-se ser dependente da própria mãe como forma de valorizar essa dependência e proporcioná-la ao filho ${ }^{(25)}$. Os depoimentos acima se inserem neste contexto de experimentar novamente a dependência da infância. Se esse processo não ocorre advém sentimentos de desamparo e desalento, dificultando a mobilização da energia emocional Que abastece o cuidado do filho prematuro. Diante da fragilidade do apoio familiar, outras fontes devem ser mobilizadas para preencher a sensação de inutilidade $\mathrm{e}$ desamparo. Esse vácuo poderia ser preenchido ou mediado pelos 
profissionais de saúde nas consultas de acompanhamento da criança. Poder-se-ia considerar o caráter dinâmico da rede social, e a possibilidade de se adequar às situações de cada indivíduo, mantendo sua integridade e identidade e também os laços e vínculos acerca de um grupo de pessoas Que fazem parte dessa rede e Que mantêm comunicação e relacionamento entre $\mathrm{si}^{(20)}$.

\section{A base segura}

Por outro lado e de acordo com os depoimentos das entrevistadas, notou-se a grande importância do apoio social em suas vidas, o sentimento de estar amparada, sentir-se segura no desempenho do papel materno.

\section{Minha sogra me abraça. (M2)}

Quem me ajudou mais foi minha mãe e minha sogra, sinto Que recebo bastante apoio, nunca fieuei sozinha. (M6)

O apoio propiciado pelas avós constitui-se num comportamento de cuidado Que promove uma base segura(26) a partir da Qual uma pessoa pode conduzir independentemente a sua vida e, Quando sentir necessidade, retornar com a certeza de encontrar a disponibilidade de pais sensíveis e zelosos. Neste caso, a base segura foi o ingrediente percebido pelas mães para ajudá-las a se tornarem mães bem sucedidas, com propensão para desenvolver comportamentos de proteção, conforto e suporte, ingredientes esses de cuidado e de sobrevivência do prematuro.

Embora, muitas vezes a manifestação do desejo de apoio, em situações adversas, possa ser vista como traço de fraqueza do pessoa. No entanto, deve-se ressaltar que a capacidade de estabelecer laços emocionais com outros indivíduos, às vezes no papel da figura Que busca ser cuidada, pode ser considerada como indicador de saúde mental ${ }^{(26)}$.

No apoio social, a vontade de ser cuidada expressa pelas mães é um dos aspectos individuais a ser valorizado, o Que facilita o compartilhamento das experiências de vida e gera bem-estar pessoal. Os componentes afetivos se tornam positivos, beneficiando cada indivíduo e realçando a sensação de pertencer a uma sociedade. $\mathrm{O}$ apoio social para Quem recebe é visto como necessário, por oferecer satisfação e interligar relacionamentos, reforçando as dimensões afetivas, emocionais e de sentimentos ${ }^{(27)}$.

\section{Apoio de informação: a busca da orientação técnica e a} valorização da informação advinda da experiência

De acordo com os depoimentos das entrevistadas, notou-se a grande importância do apoio em forma de informações. É possível Que ao se defrontar com uma nova diversidade de situações os pais sintam necessidade de reorganizar e refazer a sua rede de apoio social, na busca de pessoas mais experientes com noções técnicas e profissionais.

[... acho Que recebi toda ajuda Que precisei, perguntando pras enfermeiras e pra doutora. (M5)

[...] sempre pergunto pra minha irmã e minha cunhada Que eu mais confio. (M8)

Sempre Que preciso chamo minha sogra ou minha mãe. (M4)
A busca das informações sobre os cuidados com o filho nascido prematuramente recaiu mais nos familiares do Que nos profissionais de saúde. Isto permite o reconhecimento de Que a família está no centro das funções de cuidado e de Que grande parte do mesmo acontece no interior das relações familiares. Configura-se, portanto, como um cuidado não-profissional, Que tenta romper com o atendimento individualizado para envolver a família como sujeito autônomo de produção do cuidado na linha das relações sociais. Inclui, assim, a possibilidade de equilibrar a relação entre cuidado formal e informal e fortalecer o apoio social à mãe de crianças nascidas prematuras.

Cabe destacar a resolubilidade das orientações fornecidas pelos profissionais de saúde, segundo a percepção de uma das mães entrevistadas, o Que contribui para mostrar a importância da inserção desses atores na rede de apoio social.

\section{Apoio para interação social: a inclusão social provida pelos amigos}

Segundo o relato das entrevistadas elas têm amigos ou pessoas próximas com Quem podem se distrair e se divertir. No período puerperal mantêm atividades sociais, mas a maior parte delas gosta de ficar em casa atendendo o filho e descansando. Em Quase todos os relatos evidencia-se a normalidade da vida social:

Amigos sempre ligam pra fazer alguma janta ou almoço, eu sou mais caseira. (M7)

\section{As madrinhas do nenê sempre ligam pra fazer uma janta. (MII)}

Fazemos churrasco com os amigos, compadres. (MI2)

O apoio oferecido às famílias Que o necessitam diminui fatores estressantes e o risco de desmembramento das famílias mais frágeis, possibilitando uma seguridade maior à mãe ${ }^{(28)}$. A importância na busca por uma família unida e com saúde é um desafio às culturas e tradições, por esse motivo, o centro das atenções deverá voltarse à saúde desta família, encontrando formas de mantê-la sadia e integrada aos grupos de apoio.

Esse tipo de apoio é mais efetivo no interior das famílias, tidas como um sistema social semi-aberto, Que se mantém interligado às outras famílias ou às diferentes culturas. Neste contexto, os indivíduos se relacionam entre si para manter-se inseridos a uma determinada sociedade. Esse processo, no entanto, pode gerar tensão, a Qual, por sua vez, provoca a necessidade de reconhecer novas situações e assumir novos papéis para a transição no desenvolvimento da família ${ }^{(20)}$. Essa transição requer o apoio tanto dos serviços de saúde Quanto dos familiares, amigos, vizinhos e demais atores Que constituem as fontes de apoio e rede social ${ }^{(20)}$.

Percepção em relação à necessidade de apoio social não suprido e das situações de maior necessidade de apoio social: a ausência de apoio nos cuidados ao recémnascido e nas atividades do lar

Em alguns casos, houve a expressão de sentimentos de abandono e incompetência maternal:

e uma decepção tão grande, agora estou na pior, não tive apoio, 
precisei de alguém pra ajudar na casa não tive. (M10)

\section{Faltou um pouco de orientação até do próprio médico. (MI)}

Quando eu vim pra casa fiquei só eu e Deus, fiquei sozinha, percebi que deixaram a desejar poderiam fazer mais e não fizeram.(MI0)

\section{O primeiro dia em casa eu chorei bastante [...]. (M6)}

É bem complicado agora, tava meio assustada não sabia cuidar dele, tive dificuldade [...]. (M9)

Falar sobre as ocasiões nas Quais a necessidade de apoio foi imperativa, mas não se concretizou, deu vazão a muitos sentimentos de decepção, solidão e incapacidade. As Queixas vão da falta de orientação do profissional de saúde até a dificuldade de cuidar sozinha da criança nos primeiros dias no domicílio.

Com auxílio dos genogramas e ecomapas foi possível estabelecer a densidade dos vínculos familiares (fortes e próximos, fracos e conflituosos) e constatar Que conviver numa família estruturada, com relações interpessoais fortes, nem sempre possibilitou às mães ter suas necessidades supridas, pois os sentimentos de desamparo e decepção estiverem presentes. Neste contexto social, a mãe tem a sensação de estar sozinha e o tempo todo envolvida com as tarefas domésticas e com o atendimento das necessidades da criança, sempre repetitivas. Falta-lhe a valorização Que os familiares e amigos lhe conferiam Quando grávida. Assim, com essa frustração relacionada com as gratificações esperadas no campo social e sem muita recompensa da criança até o surgimento do primeiro sorriso, essa mãe sente-se abandonada e maternalmente incompetente. Nessas situações, o apoio social poderia devolver a essas mães a confiança pessoal, a capacidade cuidativa, a vontade de viver e a auto-estima, contribuindo com o desenvolvimento saudável da criança $\mathrm{a}^{(3)}$.

\section{CONSIDERAÇÕES FINAIS}

A percepção do apoio social interfere nos processos de adaptação da família ao nascimento de uma criança prematura, fortalecendo ou fragilizando a mãe para o desempenho de seu papel cuidativo. Neste estudo, as avós foram percebidas pelas mães como as fontes de apoio mais significativas e responsáveis pela construção social da família.

Em relação às dimensões do apoio social recebido, as mães perceberam que o apoio material foi suprido exclusivamente pelos familiares, assim como ocorreu com a dimensão afetivo-emocional percebida como uma base segura fornecida pelas avós e revestida de comportamento de cuidado, com potencial de capacitar a mãe para o desempenho bem sucedido da maternidade. Porém nessa mesma dimensão afetivo-emocional, emergiram sentimentos de desamparo e desalento, dificultando a mobilização da energia emocional Que abastece o cuidado do filho prematuro.

Na dimensão apoio de informação, a busca da orientação técnica foi percebida como uma ação resolutiva dos profissionais de saúde, embora tivesse havido predominância de informações buscadas pelas mães junto aos familiares, denotando a valorização da informação advinda da experiência, revelando a centralidade da família na produção do cuidado na linha das relações sociais.

Na dimensão apoio para a interação social, as mães perceberam o papel determinante dos amigos para a manutenção da normalidade da vida social.

Nas ocasiões em Que o apoio social não se concretizou como o desejado pelas mães, emergiram sentimentos de desamparo e decepção, especialmente Quando a mãe se sentia sozinha para prestar os cuidados à criança prematura e realizar as atividades domésticas.

Em síntese, o amparo predominantemente intrafamiliar necessita ser expandido para configurar a rede de apoio social com condições de assegurar melhor prognóstico à saúde materno-infantil. Uma vez percebendo o apoio recebido e sentindo-se amparada pelo auxílio nas atividades domiciliares, nos cuidados com a criança, na satisfação das necessidades básicas de toda a família, e também compreendida nas suas incertezas e culpas por gerar uma criança prematura, a mãe poderá se fortalecer e investir na atenção, no cuidado e na proteção à criança.

A participação ainda incipiente das instituições e profissionais de saúde, particularmente da enfermagem, precisa ser fortalecida para agregar o cuidado formal e informal em redes de apoio social inseridas numa proposta de ajuda mútua, direcionadas, especialmente, a potencializar o sentimento de competência maternal imprescindível para o crescimento e desenvolvimento saudáveis da criança nascida prematuramente.

\section{REFERÊNCIAS}

I. Winnicott DW. A família e o desenvolvimento individual. $2^{\mathrm{a}}$ ed. São Paulo: Martins Fontes; 2001 .

2. Chor D, Griep RH, Lopes CS, Faerstein E. Medidas de rede e apoio social no estudo pró-saúde: pré-testes e estudo piloto. Cad Saúde Pública 200 I;17(4): 887-96.

3. Minkler M. Building supportive ties and sense of community among the inner-city elderly: the Tenderloin Senior Outreach Project. Health Educ Q 1985; 12(4): 303-14.

4. Elsen I. Cuidado familial: uma proposta inicial de sistematização conceitual. In: Elsen I, Marcon SS, Silva MRS (Org). O viver em família e sua interface com a saúde e a doença. Maringá: UEM; 2002. p. 11-24.

5. Rocha SMM, Nascimento LC, Lima RAG. Enfermagem pediátrica e abordagem da família: subsídios para o ensino de graduação. Rev Latino-am Enfermagem 2002; 10(5): 709- 14.

6. Seco MSB, Casimiro MCSM, Pereira MIAR, Dias MIPS, Custódio SMR. Para uma abordagem psicológica da transição do Ensino Secundário para o Ensino Superior: pontes e alçapões. Leiria: Instituto Politécnico de Leiria; 2005.

7. Pinheiro MRM. Uma época especial: suporte social e vivências acadêmicas na transição e adaptação ao ensino superior [tese]. Coimbra (POR): Faculdade de Psicologia e de Ciências da Educação, Universidade de Coimbra; 2003.

8. Pope C, Mays N. Pesquisa Qualitativa na atenção à saúde. Porto Alegre (RS): Artmed; 2006.

9. Minayo MCS, organizadora. Pesquisa social: teoria, método e 
criatividade. Petrópolis: Vozes; 2001.

10. Instituto Brasileiro de Geografia e Estatística (BR). Estimativas de população. Rio de Janeiro; 2007 [citado 26 mar 2007]. Disponível em:http://home/estatistica/populacao/estimativa2006/estima tiva.shtm.

11. Prefeitura Municipal de Passo Fundo. Unidades de Saúde. Passo Fundo; 2007 [citado 26 mar 2007]. Disponível em: http:// www.passofundo.rs.gov.br/capa.php?f_cd_pagina $=172$

12. Ministério da Saúde (BR). Datasus. Cadernos de Saúde. Brasília; 2007. [citado 26 mar 2007]. Disponível em: http:// tabnet.datasus.gov.br/tabdata/cadernos/rs.htm.

13. Rocha SMM, Nascimento LC, Lima RAG. Enfermagem pediátrica e abordagem da família: subsídios para o ensino de graduação. Rev Latino-Am Enfermagem 2002; 10(5): 1-9.

14. Zuse AS, Rossato VMD, Backes VMS. Genetograma: um instrumento de trabalho na compreensão sistemática da vida. Rev Latino-Am Enfermagem 2002; 10(3): 308-20.

15. Víctora CG, Knauth DR, Hassen MNA. Pesquisa Qualitativa em saúde: uma introdução ao tema. Porto Alegre: Tomo Editorial; 2000.

16. Griep RH, Chor D, Faerstein E, Lopes C. Apoio social: confiabilidade teste-reteste de escala no estudo pró-saúde. Cad Saúde Pública 2003; 19(2): 625-34.

17. Pinto JLG, Garcia ACO, Bocchi SCM, Carvalhaes MABL. Características do apoio social oferecido a idosos de área rural assistida pelo PSF. Ciência Saúde Coletiva 2006; 1 I (3): 753-64.

18. Minayo MCS. O desafio do conhecimento: pesquisa eualitativa em saúde. São Paulo: Hucitec-Abrasco; 1996.

19. Dessen MA, Braz MP. Rede social de apoio durante transições familiares decorrentes do nascimento de filhos. Psicol: Teoria Pesquisa 2000; 16(3): 221-31.

20. Jussani NC, Serafim S, Marcon SS. Rede social durante a expansão da família. Rev Bras Enferm 2007; 60(2): 184-9.

21. Ferreira C, Viera CS. A influência do método mãe-canguru na recuperação do recém-nascido em unidade de terapia intensiva neonatal: uma revisão de literatura. Acta Scientiarum Health Sciences 2003; 25(1): 41-50.

22. Serapioni M. O papel da família e das redes primárias na reestruturação das políticas sociais. Ciência Saúde Coletiva 2005; 10 (supl): 243-53.

23. Vaux A. Social support: theory, research and intervention. New York: Praeger; 1988.

24. Ribeiro, JLP. Escala de satisfação com o suporte social. Lisboa : FPCE-UP; 1999. [citado 23 abr 2006]. Disponível em: http:/ /www.fpce.up.pt/docentes/paisribeiro/teses/socialf.htm.

25. Brazelton TB. O desenvolvimento do apego: uma família em formação. Porto Alegre: Artes Médicas; 1988.

26. Bowlby J. Uma base segura: aplicações clínicas da teoria do apego. Porto Alegre: Artes Médicas; 1989.

27. Cartana MHF. Rede e suporte social de famílias; 1988. [dissertação]. Florianópolis: Departamento de Enfermagem, Universidade Federal de Santa Catarina; 1988.

28. Vasconcelos EM. Educação popular nos serviços de saúde. $3^{\mathrm{a}}$ ed. São Paulo: Hucitec; 1999 